\title{
Avot de-Rabbi Natan B
}

\author{
Aus dem Hebräischen übers. u. hrsg. v. Hans-Jürgen Becker
}

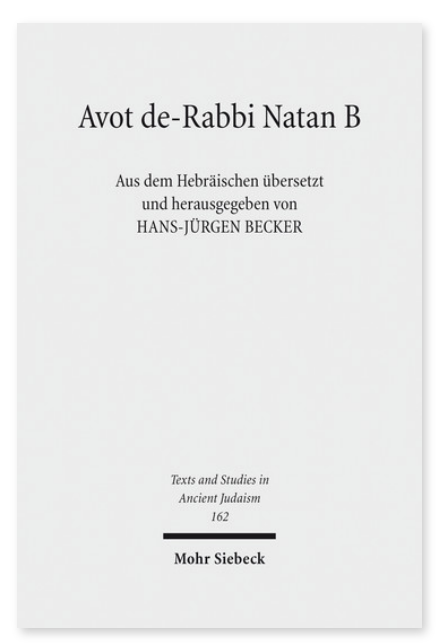

2016. V, 189 Seiten. TSAJ 162

ISBN 978-3-16-154089-9 DOI 10.1628/978-3-16-154089-9 eBook PDF 139,00€

ISBN 978-3-16-154088-2

Leinen $139,00 €$
Nach Erschließung der hebräischen Textbasis durch die Edition der Geniza-Fragmente (2003) und die Synopse der Handschriften beider Versionen von Avot de-Rabbi Natan (2006) legt Hans-Jürgen Becker mit diesem Band eine Übersetzung von Version B vor, die auf dem aktuellen Stand der Textforschung diese für Geschichtsdeutung und Weisheit des antikrabbinischen Judentums zentrale Quelle auch den Interessierten angrenzender Disziplinen zugänglich macht. Das Werk enthält unter anderem die älteste Fassung der rabbinischen Legenden zu den Umständen der Zerstörung Jerusalems im Jahre 70 n. Chr., Sentenzen und Rätselworte der Weisen des ersten und zweiten Jahrhunderts, Geschehnisse aus ihrem Leben und Schilderungen ihres Alltags mit viel Zeitkolorit, zahlreiche Gleichnisse sowie auch längere schriftauslegende Passagen, etwa zur Erschaffung des Menschen nach dem Bericht der Genesis. Fiktive Gespräche mit Kaisern, Matronen und Philosophen zeugen zusammen mit einer Vielzahl griechischer und lateinischer Lehnwörter von der Verbundenheit der Rabbinen mit der sie umgebenden Kultur.

Grundlage dieser ersten Übersetzung ins Deutsche ist die älteste und vollständigste erhaltene Handschrift MS Parma 2785 (= de Rossi 327, Spanien 1289), ergänzt durch MS Vatikan 303 (Italien, 15. Jh.). Übersetzungsrelevante Varianten sämtlicher Textzeugen werden anmerkungsweise oder durch synoptische Darstellung dokumentiert. Die Übersetzung ist um größtmögliche Wörtlichkeit bemüht - schwierige Stellen werden sprachlich nicht geglättet. Die Anmerkungen geben Hinweise zum möglichen Textverständnis, ohne der Interpretation vorzugreifen.

Hans-Jürgen Becker Geboren 1939; Studium der Rechtswissenschaft an der Universität Frankfurt am Main; 1967 Promotion; 1969 Zweite Juristische Staatsprüfung; 1972 Habilitation (Frankfurt am Main); 1975 o. Professor an der Universität zu Köln; Gastaufenthalte in Rom (Deutsches Historisches Institut) und in Berkeley, University of California (Institute of Medieval Canon Law); ab 1988 Professor für Bürgerliches Recht, Europäische Rechtsgeschichte und Kirchenrecht an der Universität Regensburg; 1992-94 Dekan der Juristischen Fakultät der Universität Regensburg; 1994-98 und 2003-05 Prorektor ebenda; seit 2008 Emeritus.

Jetzt bestellen:

https://mohrsiebeck.com/buch/avot-de-rabbi-natan-b-9783161540899?no_cache=1

order@mohrsiebeck.com

Telefon: $+49(0) 7071-923-17$

Telefax: $+49(0) 7071-51104$ 